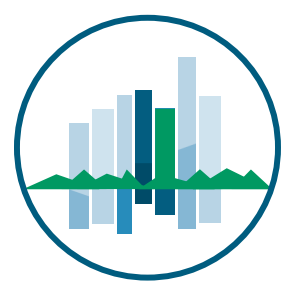

True Smart and Green City? 8th Conference of the International Forum on Urbanism
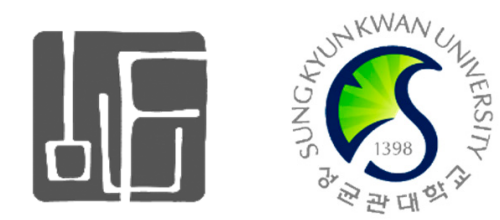

Conference Proceedings Paper

\title{
Re-Framing Resilient Urbanism. A Smart Alternative to Generic New Towns Development in South-East Asia: The Case of Hanoi (Vietnam)
}

\section{Luisa Maria Calabrese ${ }^{1, *}$, Wouter van Faassen ${ }^{2}$ and Lei $Q u^{3}$}

1 Department of Urbanism, Faculty of Architecture and the Built Environment, Delft University of Technology / Julianalaan 134, 2628 BL Delft, The Netherlands

2 Van Speijkstraat 50f, 2628 GD Den Haag, The Netherlands

3 Department of Urbanism, Faculty of Architecture and the Built Environment, Delft University of Technology / Julianalaan 134, 2628 BL Delft, The Netherlands

* Author to whom correspondence should be addressed; Tel.: +31-15-2784430;

E-Mail: 1.m.calabrese@tudelft.nl

\begin{abstract}
By presenting the case of Nam An Khanh - a typical example of a purely profitdriven New Town development in Hanoi (Vietnam) - this paper discusses the hypothesis that a more incremental and more flexible planning strategy is necessary as an alternative system for resilient urban development, in order to deal with the volatile nature of the economic and social resurrection of Vietnam. This involves a strategy that fosters socio-spatial integration and local economic growth and enables real users to be active stakeholders in this process. It involves a different kind of Urban Design, and a different kind of Urban Planning, which is less about designing or planning the product, and more about designing the most resilient possible process, a "design for self-organization."
\end{abstract}

Keywords: resilient urbanism, flexibility, design for self-organization, New Town, Asian cities 


\section{Introduction}

Flexibility in urban planning and urban design can be coined as the capacity of the built environment to adapt to new conditions in society and economy; but also as the capacity for ready physical or functional alteration and adaptation. Studies in urban theory show that flexibility is especially important when circumstances are uncertain. Circumstances may include, climate change, volatile economies, societal changes, environmental issues, etc. The hypothesis discussed in this paper is that a more incremental and more flexible urban planning approach to urban development is necessary in order to deal with the contemporary conditions of city making. This involves a strategy that fosters spatial integration, place making, local economic growth, and that enables citizens to be active stakeholders in the process of city making. It involves a strategy, a plan and a process that have the ability to be 'flexible'. In particular, this paper discusses the possibility to introduce an alternative model for New Town development, especially in the context of South East Asia. The case of Nam An Khanh, a typical example of a purely profit-driven New Town development in Hanoi (Vietnam) will serve as a test site for elaborating on this hypothesis. The assumption is that foreign-invested new urban areas have a place breaking, rather than place making effect: they disrupt the local sense of place and mainly serve extraterritorial interests (Labbé, 2010). The introduction of an alternative model for New Towns development, which could foster more flexibility in the process and design of new urban areas, constitutes an important change in mind-set towards future proof urban development. It involves an ongoing process of creating awareness of all stakeholders involved in the processes of city making, including users, developers, investors and governmental agencies. A flexible approach to urban planning and design takes the resiliency and sustainability of the city as a whole as the base, not profitability or production speed, which is an emerging perspective in contemporary Asian New Town development. The case presented in this paper shows that, with the introduction of a variety of public spaces, mixed programs and a more diverse mix of housing typologies, an alternative and more flexible urban model for New Towns can emerge. Such approach could guide South East Asian cities towards a more resilient growth in a dynamic context, ingrained in local culture, compact in its spatial layout, and give a unique identity and a concrete sense of place making and social cohesion. The introduction of the notion of flexibility - envisioned as the ability for modification and adaptation in plan and process, which is currently missing in the urban planning schemes used for New Towns - can spatially combine largescale mechanized construction and small scale, bottom-up approach of self-building housing. The case study presented in this paper discusses, by means of an hypothesis of design interventions, the possibility to develop a new model for flexible urban growth; a model that fosters flexibility from existing Vietnamese building culture, but also embraces mass production and foreign investment.

\section{Beyond Resilient Urbanism: Why flexibility matters}

The morass of contemporary polemics on how to approach ever increasing urbanization can be understood as the opposition of two essential debates. One, which still embraces the modern project of 'liberating humanity through science and rationality' (Ellin, 1996:205); the second debate asks instead, whether we should work with - and not against - nature, by understanding the city as a complex metabolism. We know that there have always been voices that spoke out against the modern project on 
the city. Those voices intensified exponentially with the rise in society of ' radical subjectivism', 'untrammeled individualism', and the search for 'individual self-realization' (Ellin, 1996:209; Harvey 1989:20). Mistrusting the viability of an overarching theory and method to universally plan, design and manage cities and citizens, observers of the post-industrial society such as Jean-Francois Lyotard, Jean Bruillard, Michel Foucault and Jurgen Habermas call for 'localized resistance' (Gutting, 2011) the development of site specific - thus not generic - approaches to city making, and more in general for social and spatial inclusiveness. Other urban thinkers, still largely accept the validity of the modern project, which is assessed in its accomplishments and pursued in its fundamental goals. We might see in the largely successful formula of the 'smart city' an example of such neo-conservatism. Maintaining that technology will assist planners, decision-makers and citizens to maximize the 'intelligence' of the space they inhabit, supporters of the smart cities movement advocate an approach to city making based on the so-called "internet of things" (the global market for which is now estimated at $\$ 1.7 \mathrm{tn}$ ) ${ }^{1}$. As a matter of fact, the dream of better living through data and other utopian urban visions help drive the smart city rhetoric that has significantly been promulgated most energetically by those who make money out of it: global technology, engineering and consulting companies.

Yet, there is criticism too. "The notion of the smart city in its full contemporary form appears to have originated within these businesses," Greenfield notes in his book Against the Smart City (2013), "rather than with any party, group or individual recognized for their contributions to the theory or practice of urban planning." Similarly, architect Rem Koolhaas, in a talk given at the High Level Group meeting on Smart Cities, Brussels, 24 September 2014, said: "I had a sinking feeling as I was listening to the talks by these prominent figures in the field of smart cities because the city used to be the domain of the architect, and now, frankly, they have made it their domain. This transfer of authority has been achieved in a clever way by calling their city smart - and by calling it smart, our city is condemned to being stupid." And he asks further: "Why do smart cities offer only improvement? Where is the possibility of transgression?"2. Actually, it is mostly unclear what for the ordinary citizen the smart city vision might mean and what role will the citizen play: "that of unpaid data-clerk, voluntarily contributing information to an urban database that is monetized by private companies? Is the city-dweller best visualized as a smoothly moving pixel, travelling to work, shops and home again, on a colorful 3D graphic display? Or is the citizen rightfully an unpredictable source of obstreperous demands and assertions of rights?" (The Guardian, December 2014). The smart city seems to be the outpost of economic neoliberalism, more than a viable urban planning model for an equitable, contemporary urban society. As such, it is a definition of city making that in our view largely outlived its usefulness.

Intellectuals, artists and even economists have sought to theorize the state of the art of global urbanization by coining new concepts and terms to define the transitional stage in which we are living in. As a matter of fact, there has been lately a flourishing of new concepts to define the contemporary condition of the built environment and how to deal with it from a planning perspective. Among those, the already discussed 'smart city', 'Anthropocene' and 'resilience' have emerged. The latest are particularly relevant to discuss the key role of 'flexibility' in city making to which this paper addresses.

Let us briefly reflect upon those two emerging concepts: Anthropocene and Resilient Cities. Anthropocene is an apt and provocative term, recently introduced in our daily vocabulary, with which to describe the era and the world we inhabit. Planet Earth has certainly entered a new epoch: the era of cities. "Humans have changed the way the world works. Now they have to change the way they think 
about it, too"3. Thanks to this invitation to drastically change the way we look at the world we live in, urban scholars, planners and designers can better place many ongoing observations about human influence on natural processes and especially on the built environment. Significantly, the announcement coming from Geologists resonates with a warning: if we expect the extraordinary achievements of human culture to survive, we have to drastically change our self-destructive planning patterns. Climate change, environmental and natural disasters, massive migrations, world economy and politics heavily and dramatically show that the traditional top-down model of spatial planning is essentially broken, noticeably vulnerable and unable of learning from its mistakes. What model of planning, designing and managing cities could be future proof?

Resilience seems to offer a way out. After 'sustainability' and 'smartness', 'resilience' is the latest proposal, which seems to present a promising answer to the challenges of contemporary urbanization. The origins of this concept are rooted in Ecology. According to Alberti (2010) "Scholars of urban ecology have hypothesized that the patterns of urbanization control ecosystem dynamics through complex interactions and feedback mechanisms linking urban activities and their spatial organization to land cover and environmental change" ${ }^{4}$. Resilience is indeed the latest global tendency and think tank to affect the study of cities to the extent that it has become a research funding council priority all over the world ${ }^{5}$. Certainly the natural catastrophes brought by climate change during the past years, which affected cities and urban populations worldwide, encouraged this new wave of resilience thinking as forming major research and policy agenda setting for the built environment. As a matter of fact, resilience as a planning and managing priority for cities is on an exponential rise with governments, NGOs, planners, managers, social scientists, ecologists, architects and engineers.

Despite the popularity of its use, there is no clear definition of what Urban Resilience is. It is now being used as sustainability has been for more than a decade, which is to say with little meaning and often as a label to fit conveniently on top of pre-existing agendas. If we look at the meaning of the word itself, resilience is a synonymous of both elasticity and buoyancy ${ }^{6}$. In the first case, it defines the power or ability (of a material) to return to the original form, position, etc. after being bent, compressed or stretched. In the second, it refers to the capacity to recover quickly from difficulties. When applied to cities, resilience most often refers to the ability of the built environment to 'bounce back' from a sudden disturbance (natural disasters, terrorist attacks, etc.). For example, in the New York City post-Sandy resilience report", "A Stronger, More Resilient New York" from the NYC Special Initiative for Rebuilding and Resilience, the focus is very much on rebuilding and recovery, a particular engineering resilience perspective (McPhearson, 2014). This is not unique to the case of New York, but it is quite common in many other cities around the world. However, there is another perspective too, rooted in Ecology, according to which the concept of urban resilience is not only about the 'extraordinary' (such as a sudden disaster), but also and foremost it is about the 'ordinary' daily life of cities and citizens. In other words, resilience is not only about recovery, but also about the ability to adapt. If we bring both perspectives together we can conclude that urban resilience is the capacity of an urban system to experience (sudden) change while retaining function, structure, feedbacks and, therefore, identity ${ }^{8}$. Such notion of what city making could be is rather comforting, inspiring and promising. However, there is critique to Urban Resilience too. Sellberg, Wilkinson, and Peterson (2015) point out that we should be careful in confusing sustainability with resilience, as they are two separate and independent notions: "understanding urban resilience and urban sustainability as two concepts that promote a plurality and 
diversity of solutions to social-ecological problems implies that urban planning needs to take on-board yet new metaphors and paradigms to further transform cities". Slater (2014) argues that we should be skeptical towards the call for being 'resilient' at any cost, as it is pure neoliberal urbanism talking. "The insidious work of urban resilience lies in the obvious and, to its proponents entirely logical policy suggestion the word carries: "urban dwellers of the world, brace yourselves for austerity [or environmental catastrophe] and everything will be fine in the end!"

The emergence of the above-discussed 'new' concepts for exploring and understanding the contemporary phenomena of massive urbanization and its consequences for the planet worldwide underlines the urgency - among scholars - to develop an entirely new knowledge system, a set of methodological approaches and operational tools to deal with the contemporary urban condition. Such a shift of perspective towards cities and city making is strongly supported by statistics, which provide evidence that more than half of the world's population now lives in cities, a figure that is set to rise to $80 \%$ by $2050 .{ }^{10}$ However, such statistics are meaningless without asking what these cities will be like, whom they are for, and how they are being made. This paper is about unraveling such questions, focusing on the case of New Towns developments in South East Asia, and in particular in Vietnam.

Since the Doi Moi policies (1987) Vietnam formally changed to a socialist market economy and adopted commercial spatial development. Because of this shift the country is facing a rapid and massive wave of urbanization. For the next 25 years, Vietnamese cities are expected to grow at an annual rate of $6 \%$, with the result that the proportion of urban population will grow from 30 to $50 \%$ (MoC, 2009). Most of this urban growth will take place in New Towns, large-scale commercial urban developments based on blueprint generic planning schemes. Such rapid growth inevitably leads to problems with the balance between demand and supply of housing stocks. Besides, it fosters a deep change in needs and demands of citizens, resulting in the disruption of the local sense of place. The scale and speed of this kind of urban developments, which serve extraterritorial interests, clashes against existing local cultures of spatial development and traditions of adaptability and self-building housing. As a matter of fact, the two existing planning models in Vietnam present clear critical qualitative issues: the self-made housing projects lack basic infrastructures and physical quality, while the massive new urban developments based on blueprint planning lack spatial and economic flexibility, local identity and social cohesion. As a result, many New Town developments in Vietnam are currently a financial, social and spatial failure. They embody the paradox between the short-term goals of developers and investors (quick profit) versus the long-term benefits of urban development for the city and its inhabitants (sustainability, livability, sense of place). The tension between short, mid and long term goals as well as between private and public interests is not specific to the Vietnamese context, as it can be found anywhere in the world where profitdriven urban development takes place. However, in Vietnam the consequences of a predominant focus on short-term development serving private interests are pressing because of the scale, typology and rate of urbanization. New Towns planned this way are developments doomed to fail, as they do not meet real users' needs. They provide a limited variety of typologies, mainly luxury housing owned by investors. In most cases no real user will ever occupy these properties with the result that many New Towns are or will become ghost towns. They are the physical embodiment of an economic bubble, which collapsed under the pressure of its own artificiality.

What's interesting for us to notice is the type of spatial planning and design approach that supports such profit-driven urban developments, namely blueprint planning. Dating back to the rational planning 
movement (1890-1960), it emphasizes the improvement of the built environment based on key spatial factors and top-down decision making by few. Examples of these factors include: sunlight exposure, transportation, standardized housing units, and proximity to green-space. To identify and design for these spatial factors, blueprint planning generally relies upon specialized technicians (including planners, urban designers, architects and engineers), and other influential groups (governmental officials and private developers). By means of the strategies associated with this elite, blueprint planning established a set of generally recognized and internationally applied rules and techniques for city making, quantitative assessment, predictive modeling, and ultimately 'design'. The modern and recent history of cities built according to this model painfully unveils its failure: spatially, socially, environmentally and economically. Besides, blueprint planning fails to pave the path for public participation, which is nowadays one key requirement for successful urban development. In both theory and practice, the shortcomings of blueprint planning are evident. We could summarize them with the 'lack of flexibility' (ready-made design, monotonous building typologies, no mix of programs, auto-oriented planning schemes, profit-driven, no sense of place and vacancy).

\section{New Town Development: The case of South East Asia}

The New Town Development model currently implemented in Vietnam is representative of the present planning trends in several countries of Southeast Asia, where Real Estate development is considered as a means for economic growth and transition. Despite the fact that the levels of economic development in Southeast Asian counties significantly vary ${ }^{11}$, New Towns seem to be the dominant model of urbanization. Whilst neighboring countries are still heavily dependent on agriculture, Vietnam is notably making steady progress in developing its industrial sectors. Among the newly industrialized countries like Indonesia and Vietnam, the industrialization and modernization processes have made New Towns a symbol of 'modernity', fulfilling the increasing demand of 'exclusive lifestyles'. With their generic spatial layout of high-end residential areas surrounded by walls, New Towns in South East Asia are, in fact, boring gated communities in rural areas, which by and large are satisfy extraterritorial interests. Housing in these New Towns is more of commodity than a human settlement. It gives to real estate developers and to the local elite opportunities for investment with huge and quick monetary profits, but no spatial or societal benefit. Sizeable prime agricultural land in urban fringe areas (e.g. Jakarta City) has been converted into sites for new towns (Firman 2004). This has, at various levels, reinforced socio-spatial segregation and environmental degradation. Due to economic crisis, large-scale housing development in the fringe areas of large cities has slowed down. In some cases, it ended up as unfinished projects, a desolated landscape of suburban unused sameness. Sadly, the outskirts of some major cities like Jakarta (Indonesia) and Hanoi (Vietnam) are therefore characterized by a number of half empty and unfinished New Towns (Firman, 2000).

This situation basically reflects a grand mismatch between supply and demand for housing. Many large developers have built luxurious houses of international standard at the outskirts, which were not required by the real housing market in the city. The layout of these New Towns very much resembles the suburban housing areas of the US, many of which were planned and designed by expatriate architects (Firman 2004) in the post WW II ${ }^{12}$. The preference for such low density and unsustainable urban model is due to the 'taste' of the majority of South East Asian wealthy speculators, to whom the suburb 
embodies the 'American Dream' in terms of wealth and lifestyle. As a consequence, they became the majority of the property owners in the mushrooming New Towns. Nevertheless, their ownership is pure speculation: none of them has the intention to live there.

New Town development can be seen as a spatial implication of urbanization processes. Rethinking such New Town development model in the context of Southeast Asian countries, especially considering its impact on society and environment, it is necessary to distinguish endogenous and exogenous factors of urbanization. According to the United Nations, Southeast Asia is one of the world's least urbanized regions. There will be at least another few decades before the level of urbanization in Southeast Asia approaches that already achieved in Europe and North America (United Nations 2001). In the past three decades, urban facilities have permeated rural areas, as the forces of modernization invaded into the agriculturally based rural communities (Jones, 2002). Real estate development in new towns from 1980s till mid-1990s basically reflects the fact that transnational capital flows freely support investment in the built environment as means of capturing and sustaining benefits (Douglass, 1998; Firman, 2004) This has brought vast and generic property development into the rural areas, where indigenous ecology and human life are accommodated by the vernacular forms of villages and the natural environment. Considering urbanization as a series of processes of transformation in built environment and society, new ways of planning and design for new urban areas are urgently needed.

\section{The Case of Nam An Khanh New Town Development in Hanoi (Vietnam)}

Hanoi is a rapidly growing city and hence the urban fringe of the city forms one huge construction site. Urban development in Hanoi has always been an incremental process of small appropriations of agricultural plots. In recent years, large-scale urban developments by multi-national consortia of urban consultants, architects and financiers, backed by the central governmental policy, became more and more predominant. Most of these developments share similar spatial characteristics: location, size and specific design choices define their slight differences. For the rest, they are all based on mono-functional blueprint layouts, with a limited number of typologies and with an investment and profit driven approach to urban development.

Nam An Khanh, our case study, is an average and typical example of the above described flaws and disadvantages of contemporary Vietnamese New Town development (figure 1a and 1b). This particular case of New Town at the outskirts of Hanoi was initiated in 2005 as a 1.5 billion dollar investment by foreign banks, government and 'others' in a publicly traded joint-stock corporation: the development consortium $^{13}$. Land was acquired from the farmers-communes, located in the neighboring villages, and shortly afterwards the land was completely cleared and infrastructure was built. The blueprint master plan of Nam An Khanh consists of a district of 1600 Spanish style villas draped around two central lakes and a set of 5-floor condominiums (2000 apartments) at the perimeter of the site. The whole area is spatially separated from the existing villages and existing road networks by fences and earthen walls. We can discern five essential problems that Nam An Khanh faced during the process of development, which typically come along with this type of New Town profit-driven developments in South-East Asia, namely: a. large financial risks; b. spatial fragmentation; c. unanswered users' needs; d. negative spinoffs on the surroundings and; d. lack of environmental consciousness (Van Faassen, 2014). These problems became painfully clear after the collapse of the housing market in 2010. 
Like many other urban developments in this region, Nam An Khanh was and is mainly a financial product aimed at maximizing private profit. A system of governmental agencies, developers and investors/speculators supported this operation. Such system worked as long as there were enough investors to cover the bills. However, in 2010 it became clear that massive overproduction of mainly expensive housing, had created an economic bubble. Housing prices dropped by $40 \%$ and investors realized that real demand from users was absent and their investment worthless. As a matter of fact, since November 2010 no new commercial housing projects are allowed in Vientnam (issued by governmental decree) and the existing ones are on hold - forced by a law of the government that aims to restore the balance supply and demand in housing stock. Nam An Khanh was also hit by the crisis: unable to adapt to the changed condition of the market, it remains $90 \%$ unfinished till the present day. This unfinished state has some unforeseen, mainly negative, effects on the surrounding villages. On the social level, there is a clear repercussion on former farmers and craft workers who, because of the sudden change of land use (from agriculture to residential), turned out to be jobless. On the spatial level, the unfinished New Town creates a strong psychical barrier between the city and the villages. On the economic level, it no longer serves extraterritorial interests and it kills local economy. All in all, this vase empty land is now emblematic of the situation in Vietnamese suburbia. A status quo with big consequences for all direct stakeholders, but also for many of the neighboring residents in the villages that have lost their means of income (agriculture). A new local economy is meanwhile hindered by spatial fragmentation in between the new and old districts, but in fact of the whole urban fringe of Hanoi (Labbé \& Boudreau, 2001). Primary infrastructure is taken care of in the master plan and major through roads are built. However, local connectivity and slow traffic networks are lacking. Foreign scholars have criticized the lack of integration between the built environments and the existing context of villages. "The resulting urban fragmentation is commonly blamed on the imposition of foreign models of urban development that promotes a break with previous urban space production mechanisms" (Labbé 2010): gated communities, mono-sprawl of a limited number of typologies, social and economical segregation and purely profit based development have produced an urban patchwork of islands separated by large boulevards. Connectivity on the small scale is lost.

The case of Nam An Khanh, illustrates the fragility of generic blueprint planning, which is rapidly becoming the standard of urban development in Vietnam. Like in other Asian cities, Hanoi implemented a scheme of New Town development in a ring around the city as a response to its growth (figure 2). This scheme allowed the development of purely profit-driven large blueprint extensions, which are mostly monotonous, mono-functional and speculative in nature. The result is that new urban expansions in Hanoi do not respond to the needs of real users: overproduction of high-end housing led to vacancy. Ghost towns have become a serious social, financial and ethical problem, which is asking for an alternative planning approach (figure 3).

\section{The Flexible City: Towards an integrated and inclusive planning and design approach to city making}

In our view, in order to gain greater resilience in New Town planning and design under those circumstances, it is crucial to understand and clarify the importance of creating and maintaining a balance between the main stakeholders in the process: governmental agencies, investors, project developers, 
adjacent inhabitants and local entrepreneurs. This 'balance' involves a strategy that fosters socio-spatial integration and local economic growth and that enables real users to be active stakeholders in this process, by engaging them in decision making and co-development of their own city. Significantly, it involves a different understanding of what Urban Design is. And it requires as well a different definition of Urban Planning, which is less about designing or planning the end product, and more about designing the most resilient possible process in order to create a more resilient and sustainable 'open end product' (incremental and sustainable urban growth). The Flexible City might offer an interesting and viable alternative to the failed New Town. It is based upon the observation that worldwide most of contemporary urban development is 'temporary' (Bergevoet Van Tuij1, 2013), which means that the time span of the realization of an urban project may vary: it could be one month, a year, ten years, 40 years or even longer. In the end, the city will change and adapt to new needs, regardless of the time span of realization of urban projects, which may become obsolete even before completion. If urban development does not take place at once, but in small, incremental steps, a certain degree of 'maneuverability' could be reached in city making.

During various design and research experiments (Van Faassen, 2014) we came up with an array of solutions and tools for a more resilient approach for the future (re-)development of Nam An Khanh. By focusing on the notion of flexibility in a. the process $b$. urban planning and c. urban design we set up a framework (process/planning/design), whose main characteristic is to be strong enough to support a multitude of strategies and design solutions that leave space for later interpretation and elaboration in the case that circumstances may change. Also, the framework ensures spatial and social quality. It secures a sustainable balance between (financial) power and influence of other stakeholders. In order to step away from theoretical debates, the proposal is made very concrete; it tackles problems of governance, planning and design step by step, and therefore becomes understandable and acceptable for all involved. The next paragraph will give a summary of our approach to develop a framework for the Flexible City (based on the case of Nam An Khan).

The current unfinished state of Nam An Khan has to be acknowledged as a new urban reality. It will never be finished in its current form. However, it is also clear that Nam An Khanh cannot be re-developed directly or in one go. Therefore, a strategy for temporary use of the empty housing stock and public space becomes necessary. Temporary functions, like flower gardens or festivals can be used as an instrument for 'place making' in order to create a positive image of the site for potential buyers. Temporary use can also be used as a social gesture to the neighboring villagers. Gardens could give citizens an outdoor weekend retreat for the next 10-20 years. A well-designed fruit orchard is an inexpensive way of making a beautiful spring park, while providing some jobs to the villagers (figure 4). The remaining empty areas can be used for events and festivals, or even as research site for innovative agriculture. These temporary uses help to build a good image of the location and attract people, and therefore improve the conditions for new initiatives. The first step to improve connectivity and integration is to connect the villages and Nam An Khanh with a secondary road network that fosters the local economy and community. Urban catalysts in Nam An Khanh are special places like a market hall for fresh local products, or a modern Arts Center with ateliers, and expositions (figure 5). Their function is twofold: a. to catalyze local economic activities and; $b$. to be the starting point of a neighborhood cluster. Clustering residential areas around an urban catalyst is a way of fostering local community in neighborhoods. The re-design of these clusters/neighborhoods are based on two elements: the framework 
and the infill. The framework is made of a structure of main roads, secondary roads, transit, water networks and parks. The infill is the flexible redevelopment of the unfinished (or empty) residential blocks. The infill is regulated with a zoning that fosters a mix of uses and typologies. The scale of the incremental re-development is deliberately kept small to prevent large accumulations of means - in this way the neighborhood can, in time, easily be adapted to the changing needs of its inhabitants. Each neighborhood has its specific flexible strategy for development, embedded in a vision for the general direction of the spatial quality and living environment and regulations that guide this development. The strategy does not only rely on prohibiting certain typologies and uses, but more on allowing and even showing potentials for a variety of uses that are not directly in the plan. Sustainable development for the environment and the community can in this way be an incentive for developers that want to build more, or with special qualities.

Based on the results of test case Nam An Khanh, we argue that the plan for a Flexible City must include flexibility in the process as well as in the planning and design. The planning and design of the Flexible City has no fixed, finalized form: it offers a clear and strong strategic and spatial framework, which guarantees the overall quality of public spaces and connections, and at the same time it leaves open opportunities for infill and participation. The Flexible City is dynamic and able to accept and incorporate change. The Flexible City grows incrementally. In its physical, social and economic structure it incorporates resilience, smartness and sustainability. The Flexible City has a clear and strong meaning, guaranteed pre-condition for further development - infrastructure network, to ensure sustainable and equitable mobility, the quality of public spaces and variation in typologies for infill. The flexible City is never generic, it relies upon the physical, social, cultural and economic local resources, maximizing its uniqueness. As such, it refuses the conventional urban planning at large following a technocratic pattern in order to define zoning and uses and standards. In the Flexible City the urban project overrules the fixed blueprint urban plan. The urban project refers to design at an intermediate scale of 'urban catalysts' with specific programs of common interest to the community. In the Flexible City the gap between urban planning, urban design and architecture is solved at the intermediate scale (in design) and in multi-actors participation (in process). The Flexible City is based on the following principles:

- connectivity and integration;

- presence of urban catalysts (priority of development);

- temporary use as place-making tool;

- fostering local community in neighborhoods;

- diversity in users, building typologies and developers;

- strong framework (mobility networks and public spaces) + flexible infill (programs/variations of building typologies).

\section{Conclusions}

Resilient Urbanism is a broad concept that seeks to explore a wide spectrum of topics related to what makes resilience in urban contexts unique: spatial challenges, social and economic equity, climate change, density, mobility, governance, and other characteristics related to the unpredictable and everchanging urban environment. It proposes a vision of Urban Planning and Urban Design as responsive - 
and therefore implicitly 'smart'- to the volatile contexts of contemporary cities and regions through a variety of scales and time frames. However, in order to make our cities truly intelligent, we need to reframe the theoretical notion of 'resilience' in terms of concretely 'smart' planning and design actions.

Figure 1. (a) Original Master Plan of Nam An Khanh New Town Development. (b) Bird view of Nam An Khanh, current situation.
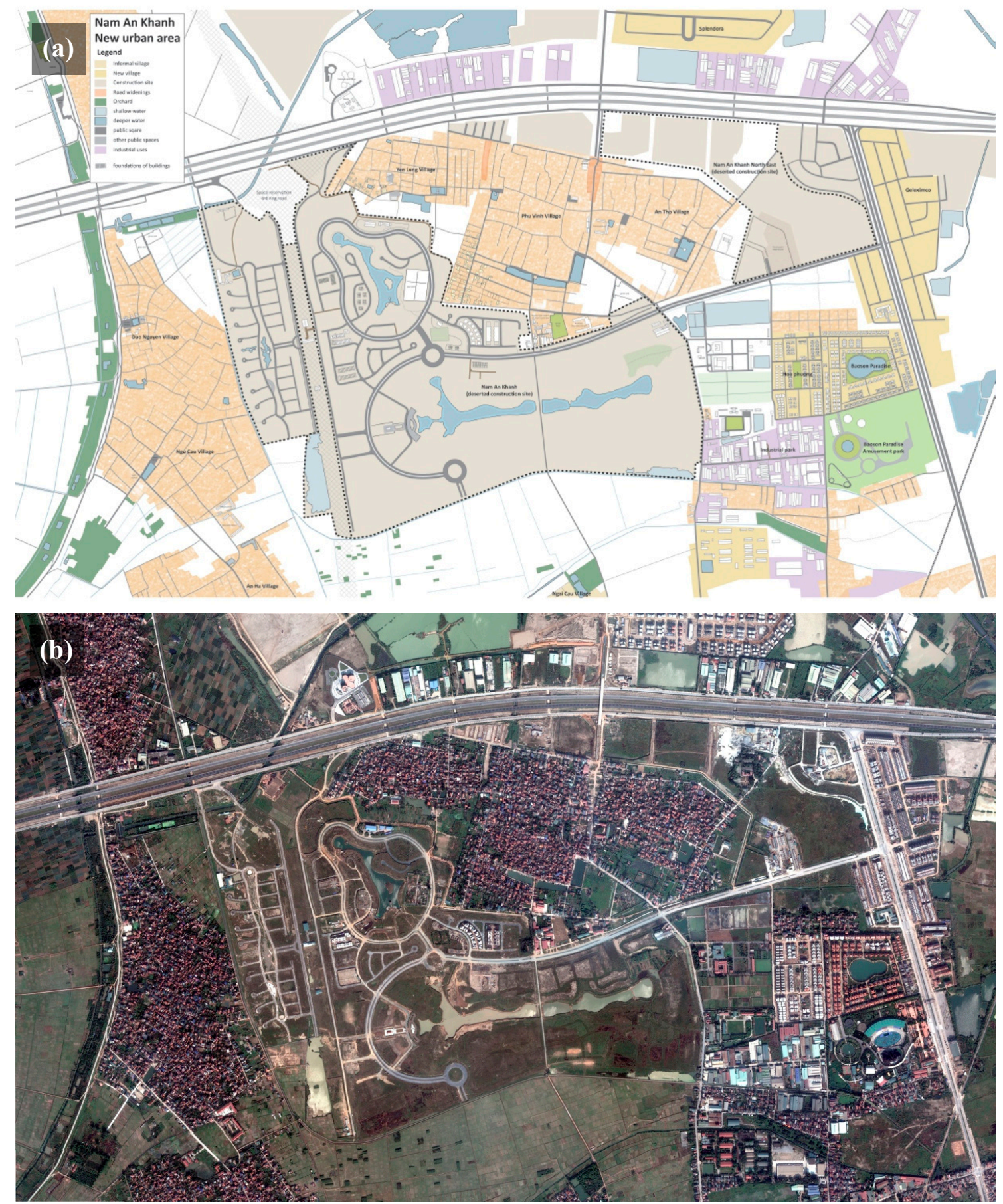

As Jane Jacobs argued back in in the 1960's, and Nassim Nicholas Taleb recently confirmed (The Black Swan, 2007), the traditional top-down model of Urban Planning is essentially broken, noticeably vulnerable and unable of learning from its mistakes. The case of generic New Towns development in South-East Asia painfully illustrates such fragility. In this paper we discussed, by using the case of Nam 
An Khanh (Hanoi), the possibility to foster an alternative model to urban development, that of the Flexible City, which involves tan integrated and inclusive planning and design approach to city making.

Figure 2. Hanoi Capital Construction Master Plan to 20130 and Vision 2050 (Perkins Eastman (2011).

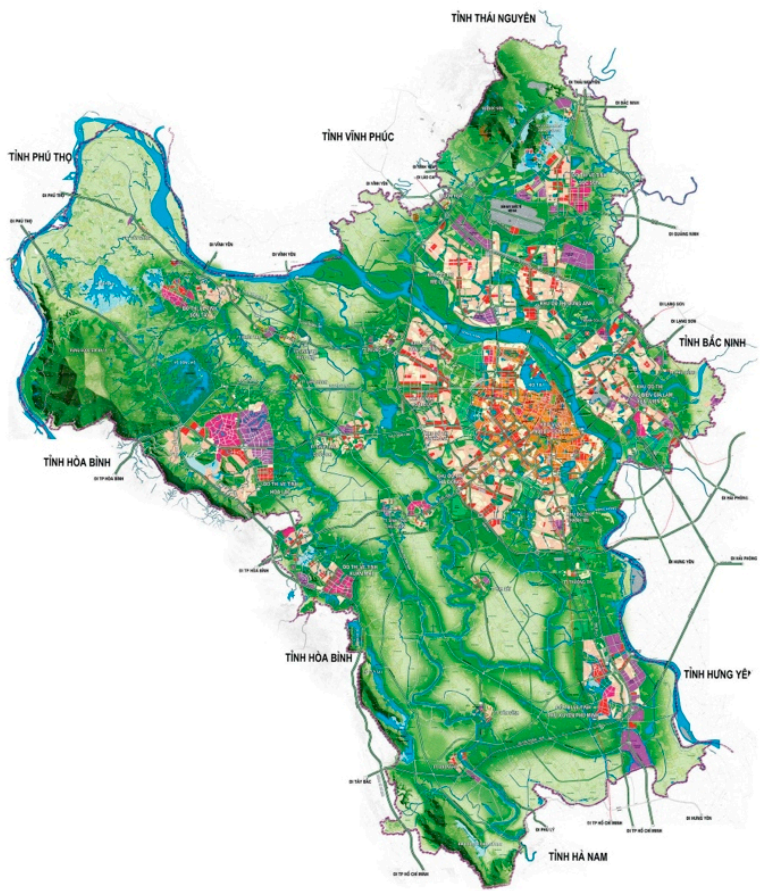

Figure 3. Nam An Khanh: South view of current situation (photo by W. van Faassen, 2013).

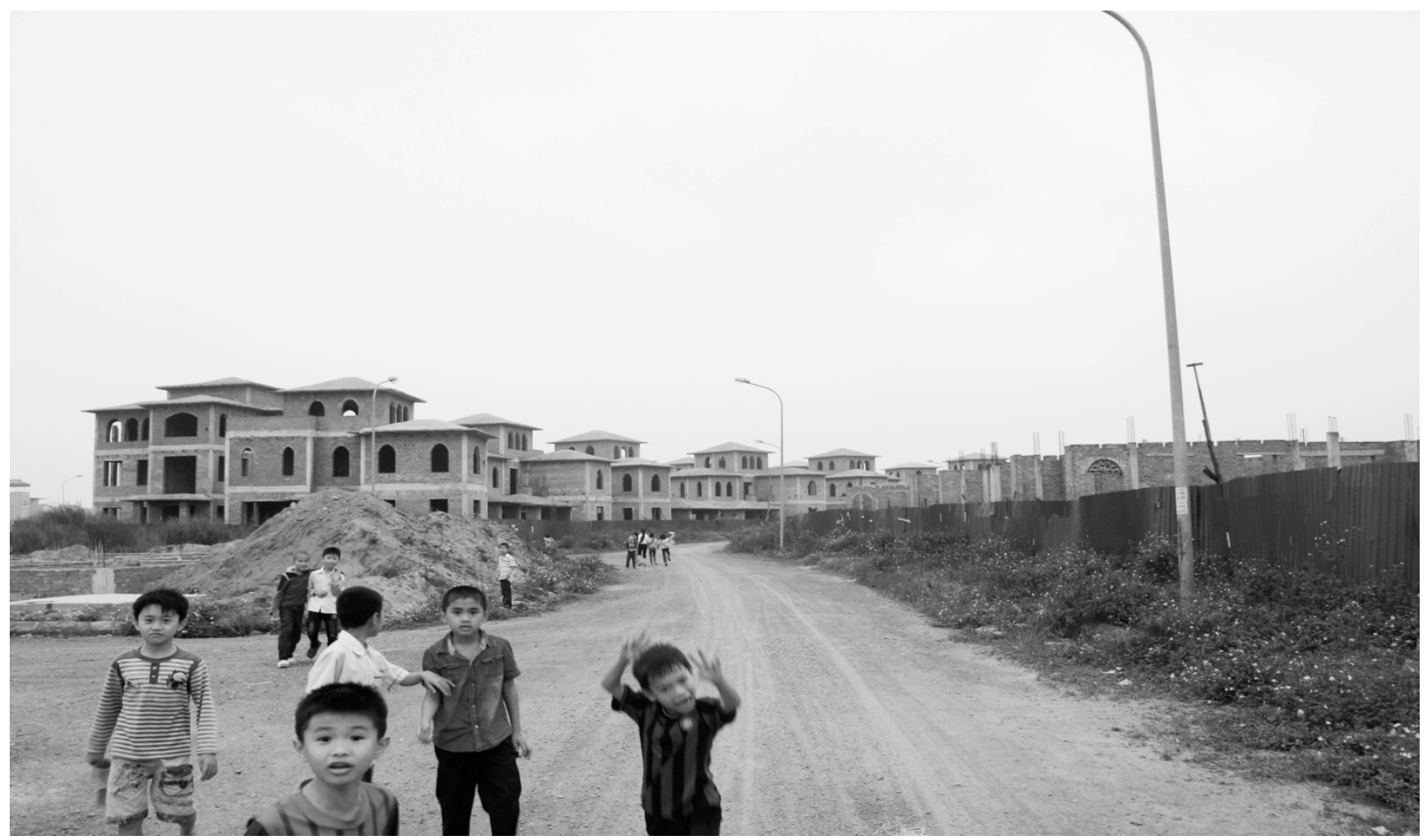


Figure 4. Nam An Khanh: Proposal for temporary functions in public spaces. (W. van Faassen, 2014).

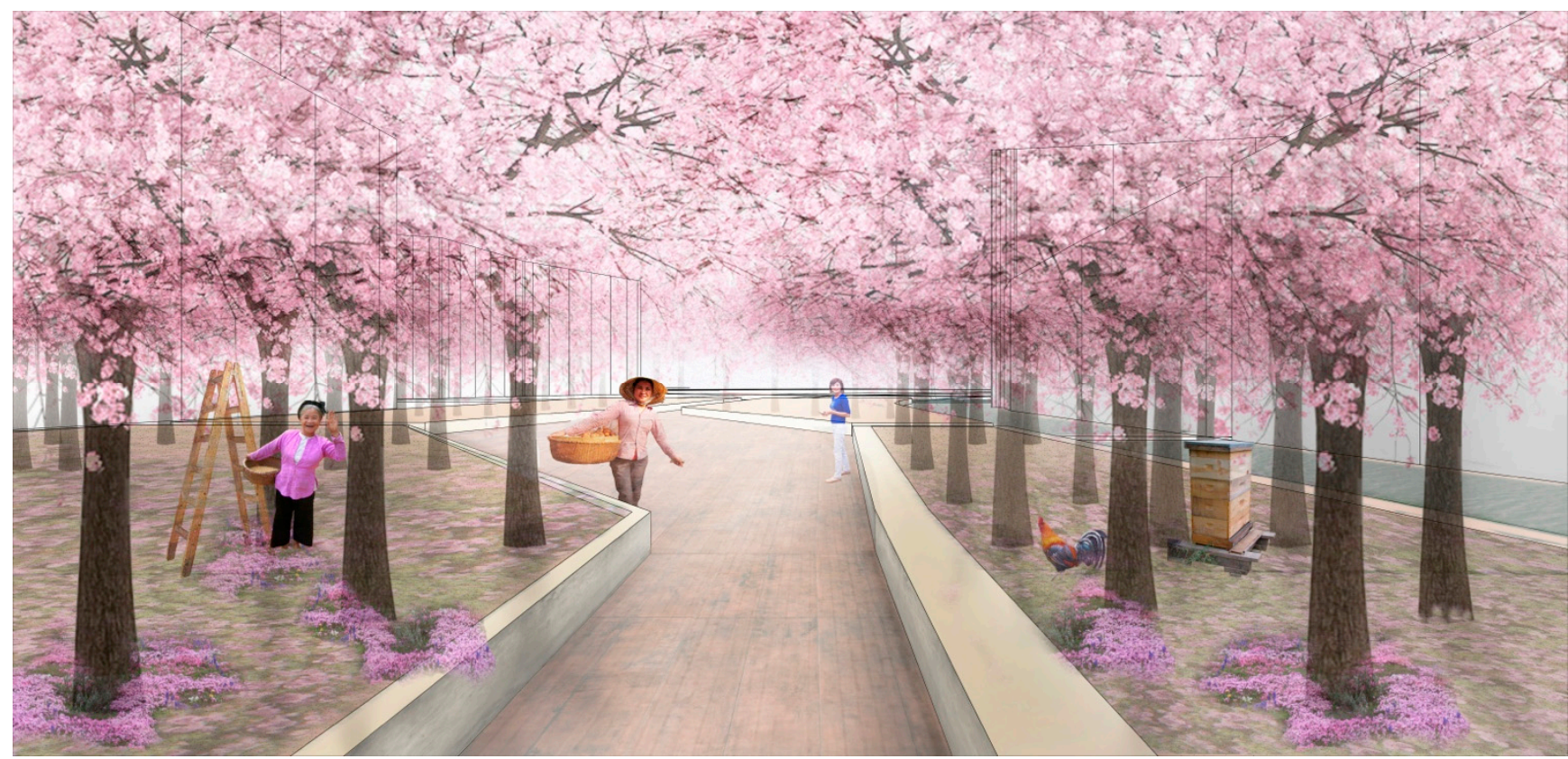

Figure 5. Nam An Khanh: an example of urban catalyst, a modern Arts Center with ateliers and exposition facilities. (W. van Faassen, 2014).

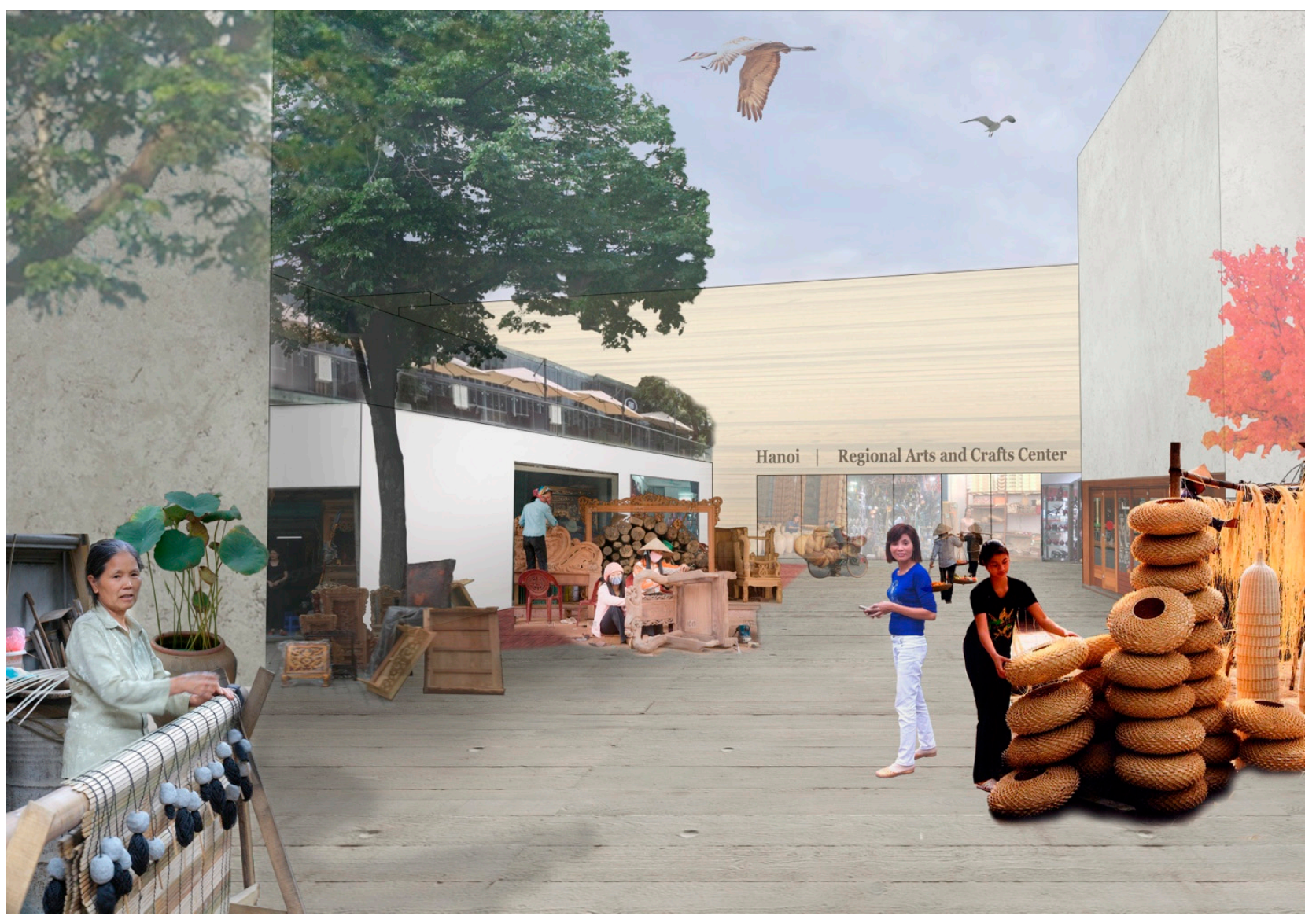




\section{Conflict of Interest}

The authors declare no conflict of interest

\section{Notes}

1. http://www.theguardian.com/cities/2014/dec/17/truth-smart-city-destroy-democracy-urbanthinkers-buzzphrase. Accessed March 252015.

2. http://ec.europa.eu/archives/commission_2010-2014/kroes/en/content/my-thoughts-smart-cityrem-koolhaas.html. Accessed March 232015.

3. The Economist, Welcome to the Anthropocene, The Economist Print edition May 28th, 2011.

4. Alberti, M., Maintaining ecological integrity and sustaining ecosystem function in urban areas 2010, Current Opinion in Environmental Sustainability, 2, Issue 3, 178-184.

5. Recently, the Urban Europe "Joint Programming Initiative" was released, inviting proposals on broad topics, among them "Urban Vulnerability, Adaptability, and Resilience", where projects will "enhance understanding of and response to natural, environmental, social, economic and technological shocks as well as gradual changes". Source: http://jpi-urbaneurope.eu. Another example is the "100 Resilient Cities", pioneered by the Rockefeller Foundation (100RC), which is dedicated to helping cities around the world become more resilient to the physical, social and economic challenges that are a growing part of the 21 st century. 100RC supports the adoption and incorporation of a view of resilience that includes not just the shocks - earthquakes, fires, floods, etc. - but also the stresses that weaken the fabric of a city on a day to day or cyclical basis. Examples of these stresses include high unemployment; an overtaxed or inefficient public transportation system; endemic violence; or chronic food and water shortages. By addressing both the shocks and the stresses, a city becomes more able to respond to adverse events, and is overall better able to deliver basic functions in both good times and bad, to all populations. Source: http://www.100resilientcities.org

6. http://www.oxforddictionaries.com/definition/english/resilience. Accessed March 292015.

7. http://www.nyc.gov/html/sirr/html/report/report.shtml. Accessed March 252015.

8. McPhearson, T., The Rise of Resilience: Linking Resilience and Sustainability in City Planning, http://www.thenatureofcities.com/2014/06/08/the-rise-of-resilience-linking-resilience-andsustainability-in-city-planning/ 2014

9. Slater, T., The resilience of neoliberal urbanism, https://www.opendemocracy.net/opensecurity/tom-slater/resilience-of-neoliberal-urbanism, 2014

10. Dowe, M., Urbanisation and Climate Change, https://markdowe.wordpress.com/.../urbanisationand-climate-change. Retrieved April 16, 2015.

11. From newly industrialized countries like Indonesia, Malaysia, Thailand, and the Philippines, to affluent and developed economies including Singapore and Brunei.

12. In The US, as automobiles became more widespread, there was political and economic pressure to expand the road network. In 1958 the Interstate Highway Act connected all the major cities in the US with highways. A demand for housing, particularly single-family homes, was met in the United States with government loans and other incentives to expand housing in suburban areas. Life in the suburbs became feasible with the automobile, which provided mobility everywhere, anytime. Thus, 
after World War II, at least in the United States, the automobile, the auto industry, the urban road network, and the suburbs grew together. The result was a dispersed urban geography, often called sprawl, which characterized not only the suburbs of large cities but also whole cities that experienced the bulk of their growth after the automobile became popular, they include Phoenix, Arizona; Los Angeles, California; Dallas, Texas; and Orlando, Florida. This is a geography in which travel is less focused on nodes and corridors (denser, centrally located city and suburban downtowns). It is a dispersed market that is difficult to serve economically with mass transportation.

13. http://vnre.blogspot.nl/2008/04/nam-khanh-new-urban-area-realizing.html. Accessed March 25 2015.

\section{References}

Alberti, M., Maintaining ecological integrity and sustaining ecosystem function in urban areas 2010, Current Opinion in Environmental Sustainability, 2, Issue 3, 178-184.

Bergevoet, T. \& Van Tuijl, M. (2013) De flexibele stad, Oplossingen voor leegstand en krimp. Rotterdam, NAI010 Publishers: Rotterdam, The Netherlands, 2013.

Douglass, M., Urban and regional policy after the era of naive globalization. Paper presented to global forum on regional development policy. The United Nations Center for Regional Development 1998, Nagoya, 1-4 December.

Ellin, N., Postmodern Urbanism, revisited version, Princeton Architectural Press: New York, USA, 1996 Faassen (van), W., Flexibility: an alternative development strategy in new urban areas in Hanoi, MSc Thesis, Delft University of Technology: Delft, The Netherlands, 2014

Firman, T., Rural to urban land conversion in Indonesia during boom and bust periods. Land Use Policy 2000, 17(1), 13-20.

Firman, T., New town development in Jakarta Metropolitan Region: a perspective of spatial segregation. Habitat International 2004, 28(3), 349-368.

Geertman, S., The self-organizing city in Vietnam: processes of change and transformation in housing in Hanoi. PhD dissertation, Eindhoven University of Technology: Eindhoven, The Netherlands, 2007.

Gutting, G., Thinking the Impossible. French Philosophy since 1960, Oxford University Press: Oxford, United Kingdom, 2011.

Harvey, D., The Condition of Postmodernity. $1^{\text {st }}$ ed., Blackwell Publisher: Oxford, United Kingdom, 1990.

Harvey, D., The Urban Experience, John Hopkins University Press: Baltimore, USA, 1989.

Jones, G.W., Southeast Asian urbanization and the growth of mega-urban regions. Journal of Population Research 2002, 19 (2), 119-136.

Labbé, D.; Boudreau, J. Understanding the causes of urban fragmentation in Hanoi: the case of new urban areas. International Development Planning Review 2001, 33(3), 273-291

Labbé, D., Facing the urban transition in Hanoi: recent urban planning issues and initiatives. Montreal Centre - Urbanisation Culture Société, January 2010. 
McPhearson, T., The Rise of Resilience: Linking Resilience and Sustainability in City Planning, http://www.thenatureofcities.com/2014/06/08/the-rise-of-resilience-linking-resilience-andsustainability-in-city-planning/ 2014

Sellberg, M. M., C. Wilkinson, and G. D. Peterson. Resilience assessment: a useful approach to navigate urban sustainability challenges. Ecology and Society 2015, 20(1), 43.

Slater, T., The resilience of neoliberal urbanism, https://www.opendemocracy.net/opensecurity/tomslater/resilience-of-neoliberal-urbanism, 2014

Taleb, N.N., The Black Swan: the Impact of the Highly Improbable,1st ed.; Random House: New York, USA, 2007.

United Nations, World Urbanization Prospects as Assessed in 2001. UN, New York, USA, 2002.

(C) 2015 by the authors; licensee MDPI and IFoU, This article is an open access article distributed under the terms and conditions of the Creative Commons Attribution license. 